\title{
China's New Mainstream Blockbusters' Characteristics and Trends from the Perspective of Film Industry Aesthetics in the Post-Industrial Era
}

\author{
Lu Yu1), Shanyue Jin2), Songjuk Kim³)
}

\begin{abstract}
As China became a post-industrial society in 2015 , with the development of the film industry, establishing the concept of "film industry aesthetics" is becoming increasingly important. At the same time, as the soft power has become more significant in the international arena, and several Chinese new mainstream blockbusters (CNMB) have suddenly sprung into the box office, making it worthy of attention. CNMB are inseparable from the construction of film industry aesthetics. This paper first explains the relationship between the three concepts - post-industry era, film industry aesthetics and CNMB. Some places of CNMB follow the principles of film industry aesthetics. With the concepts of a Community of Shared Future for Mankind and the China Dream proposed by Chairman Xi Jinping in 2012, the themes of CNMB have been upgraded, presenting many new features and reflecting mainstream values of the rapidly developing Chinese society. Therefore, this study also determines the new characteristics of CNMB. At last, the author reports their development trends in the post-industrial era. This paper hopes to provide reference values to their development, and also to the method of how to form a cultural characteristics of a country and its image and convey its mainstream values in the country and the world. This is beneficial to a country's cultural output and improvements of soft power. It also conforms to the development of China's national "Belt and Road" strategy. This paper uses literature research and an interdisciplinary approach to clarify the correlation between the concepts and the contexts, and then uses the method of generalizations and contrast to sum up CNMB features from the perspective of film industry aesthetics. Furthermore, this paper adopts the literature research method to point out that in the background of the post-industrial era and its development trends, it adopts the method of data analysis, comparison of form, and typical case study. By these research methods, it is found that $\mathrm{CNMB}^{\prime}$ some places are similar to the aesthetics of the film industry. But with the development of the era, there are new characteristics of CNMB. Under industrial rules in the post-industrial era, it should strengthen ways to convey the mainstream values of a country to the world and, thus, enhance a country's soft power.
\end{abstract}

Received(February 03, 2020), Review Result(1st: March 04, 2020, 2nd: April 28, 2020), Accepted(May 27, 2020)

1) (Ph.D Candidate) 05006 Dept. Performing Art · Film Art · Comic \& Animation, Sejong Univ., 209 Neungdong-ro, Gwangjin-gu, Seoul, Korea email: 710975265@qq.com

2) (Assistant Professor, Corresponding Author) 13120 Dept. Global Business, Gachon Univ., 1342 Seongnamdaero, Sujeong-gu, Seongnam-si, Gyeonggi-do, Korea

email: jsyrena0923@gachon.ac.kr

3) (Associate Professor) 13916 Dept. Hotel and Tourism, Daelim Univ., Imgoklo 29 Dongan-gu, Anyang-si Gyunggi-do, Korea

email: jszh1009@daelim.ac.kr 
China's New Mainstream Blockbusters' Characteristics and Trends from the Perspective of Film Industry Aesthetics in the Post-Industrial Era

Keywords: Post-Industrial Era, Film Industry Aesthetics, China's New Mainstream Blockbusters, Mainstream Values of a Country, Soft Power

\section{Introduction}

Based on real-time box office data of Chinese films, the highest-ranking film in Chinese film history is Wolf Warrior 2, which was released in the summer of 2017 and earned $\$ 0.80$ billion (domestic). CNMB, including Wolf Warrior 2, account for five of the top ten Chinese films ranked in box offices. This phenomenon deserves attention and further study. Meanwhile, in the "China Golden Rooster \& Hundred Flowers Film Festival film forum" in 2017, educational circles started to establish a "film industry aesthetics" discourse system. "In the new era, the establishment of a Chinese characteristic film industry system" has also been a Chinese Social Science Fund Research Project. Thus, this affirms that the concept of "film industry aesthetic" is increasingly important. With the globalization level continuously increasing and the simultaneous "high-level Belt and Road" policy, China needs to build a body through which its mainstream values can be shown to both China and the world. As the film industry, CNMB is the best option. Since 2015, China has entered a post-industrial stage[1]. In the post-industrial era, the sustainable and long-term high growth of China's economy relies more on the development and growth of the "soft" service sector, especially the knowledge-based modern service sector. The film industry is a "soft" culture industry that also belongs to the "soft" knowledge-based modern service sector. The development of the film industry in the post-industrial era is not only beneficial to the stable growth of the country's economy, but also to the substantial improvement of China's soft power in the world. The construction and development of $\mathrm{CNMB}$, as a film industry, is in line with the requirements of this era. There are only four articles on the study of China's new mainstream blockbusters from the perspective of film industry aesthetics. To sum up, it is of great significance and value to study this topic. After studying the rules for the creation of CNMB, this paper finally suggests future trends of their development in the post-industrial era. We begin with an examination of the relevance of the concepts.

\section{The Concepts and Relevance}

The post-industrial era is unlike the era of industrialization. In an industrial society, with the help of science and technology and the industrial revolution, the subjectivity of people's initiatives was fully revealed, such as taking a mechanistic or physicalist views of nature, and 
emphasis on using and conquering nature. The industrialized civilization has made us re-examine the relationship between humans and nature, with more emphasis now on respecting, adapting, and protecting nature so as to realize harmonious coexistence between humans and nature, improved human health, and sustainable development. There are two main indicators of the transition from the industrial age to the post-industrial age. First, the output value of the tertiary industry exceeds that of the secondary industry, and second, that there are more white-collar workers than blue-collar workers[1]. According to this standard, China entered the post-industrial stage in 2015. In post-industrial society, cooperation and exported economic benefits are the main characteristics, as discussed in detail in the fourth part of this article. Against this background, the film industry-a tertiary industry-is facing big opportunities, with its development beneficial to "soft power" and the economic development of post-industrial era society.

The concept of Chinese film industry aesthetics is divided into several levels. First, it is a film industry. Chen Xuguang, who is vice president of art school of Peking University, says that it adheres to the genre film production principles, weakens private, emotional, and self experiences in film production, and replaces with them standardized and rational ways of working. It commits to the producer-centered system. Second, it is an aesthetic. The final modifier text focuses on aesthetics, but specifically, what kind of aesthetics? Film industry aesthetics are a balance between industry and aesthetics; not elitist and small-circle elegant, minority-appealing aesthetics and culture, but aesthetics that pay attention to mass culture, 'average' and not-so-prominent individual styles[2]. Film industry aesthetics follow a process in the field of film production, but at the same time, try to give consideration to the pursuit of artistic beauty in film creation[3]. Third, Chinese film industry aesthetics embody Chinese characteristics and values. The CNMB that this paper focuses on express the Chinese mainstream values of today's society - an important force to construct the Chinese film industry aesthetics.

What are the CNMB? They are films full of positive energy, close to the masses, with strong dramatics, and stories with conflicts. They include national ideas expressed in a global perspective, the appearance of A-list stars, the promotion of tense action, the presentation of international locations, and the ups and downs of the narrative with other elements that jointly complete the overall structure of the new mainstream blockbuster[3]. Zhao Weifang stressed that there are two important foundations of CNMB. The first is the mainstream value. Mainstream films are bound to show mainstream values, including the global concept of Chinese socialist value outlook. The second is genre. The new mainstream blockbusters must be 
China's New Mainstream Blockbusters' Characteristics and Trends from the Perspective of Film Industry Aesthetics in the Post-Industrial Era

created by genre to meet the requirements of popularity and production quality. These characteristics have been fundamental to the concept since its inception[4].

CNMB have relevance with Chinese film industry aesthetics. The audiences of CNMB are the masses, and the investment is large. Therefore, innovation must be constructed and developed according to the concept of film industry aesthetics. Popular commercial expression and industrialization, along with standardized production, are indispensable factors. As per the aforementioned $\mathrm{CNMB}$ characteristics, the top ten highest box office films in Chinese film history include Wolf Warrior 2 (\$0.80 billion), The Wandering Earth ( $\$ 0.66$ billion), Operation Red Sea ( $\$ 0.52$ billion), My People, My Country ( $\$ 0.42$ billion), and The Captain ( $\$ 0.41$ billion). Five of the top ten films are $\mathrm{CNMB}$, which indicates that they have already begun to dominate. However, the box office is not the only aspect by which a film's success is judgedit should also embody aesthetic characteristics and innovation. Based on film industry aesthetics, some $\mathrm{CNMB}$ adopt certain characteristics, while others are new. Does this raise the question as to what are the detailed characteristics of CNMB?

\section{Aesthetic Characteristics of Chinese New Mainstream Blockbusters}

\subsection{Similarities to Film Industry Aesthetics - Aesthetic Usualness}

Firstly, CNMB are consistent with film industry aesthetics in the producer-centered system. Let's consider the producers of the five CNMB in the top 10. Lv Jianmin, producer of Wolf Warrior 2, has long-term film production experience. Gong Geer, producer of The Wandering Earth, was taught in the public utility management of Beijing Film Academy and was professionally trained. Yu Dong was the producer of Operations Red Sea, while well-known producers Huang Jianxin and Yu Dong formed the big production team for My People, My Country. The Captain also had a famous producer team. Without exception, film producer teams are well known and/or professionally trained. The team producer coordinated and arranged the project from the stage of financing to shooting and production, and was responsible for post-production publicity, release, and post-production development. With global consciousness, films can be industrialized smoothly. As Hong Kong veteran film director and producer Wu Siyuan says, "under the director-centered system, the success of the film industry is accidental, while under the producer-centered system, the success of the film industry is inevitable[5]."

Secondly, the star effect is also a feature of CNMB. In addition to famous movie stars, the 
behind-the-scenes director cast of My People, My Country also lights up the entire film, with a team of five established directors, Chen Kaige, Zhang Yibai, Guan $\mathrm{Hu}, \mathrm{Xu} Z \mathrm{Zheng}$, and Ning Hao. Similarly, both Operation Red Sea and The Captain, Wolf Warrior 2 feature a number of well-known, familiar stars joining the performance. According to statistics, there are on average nine A-list directors and actors in the five new mainstream blockbusters that are ranked top ten in China, and 17 A-list directors in My People, My Country. Actors are enthusiastic about participating in films that celebrate the birth of the motherland, and due to the films' big budgets and high marketability, $\mathrm{CNMB}$ are strongly appealing to the stars. Therefore, due to the nature of $\mathrm{CNMB}$, they embody the feature of having big star casts.

[Table 1] Number of A-List Stars and Directors in the Top 5 CNMB

\begin{tabular}{|c|c|c|c|c|c|}
\hline & $\begin{array}{c}\text { Wolf Warrior } \\
2\end{array}$ & $\begin{array}{c}\text { The } \\
\text { Wandering } \\
\text { Earth }\end{array}$ & $\begin{array}{c}\text { Operation Red } \\
\text { Sea }\end{array}$ & $\begin{array}{c}\text { My People, } \\
\text { My Country }\end{array}$ & The Captain \\
\hline $\begin{array}{c}\text { Number of } \\
\text { A-list stars } \\
\text { and directors } \\
\text { in the film }\end{array}$ & 8 & 5 & 6 & 17 & 8 \\
\hline
\end{tabular}

Thirdly, $\mathrm{CNMB}^{\prime}$ dependence on film technology. With the development of science and technology, films can restore scenes from the creator's mind. The space scene in The Wandering Earth, the grand scene and explosion effect in Wolf Warrior 2 and the creation of the disaster effect in The Captain show that film technology has been an important part of the film presentation quality of CNMB. Notably, the development of film technologies such as realistic special effects technology and 3D technology have made it possible for the film industry to become an industry, and in the future, VR technology is also expected to be properly integrated. The entire earth world in The Wandering Earth is set in the future and virtual, including the underground city and the frozen city on the ground. Although it includes Beijing, Hangzhou, and other urban imprints, these are based on the actual ground but highly enhanced with special effects. In the space station, the existence of Jupiter is manifested entirely using special effects. We found that in the five aforementioned CNMB, the realization of the heroic deeds of all the main characters and the structure of the story are inseparable from the special effects technology, such as Leng Feng in Wolf Warrior 2, Liu Qi in The Wandering Earth and so on. These films are generally big-budget, have big-market publicity, are technically in line with the aesthetics of the film industry, and rely on special effects technology to achieve the narrative. 
China's New Mainstream Blockbusters' Characteristics and Trends from the Perspective of Film Industry Aesthetics in the Post-Industrial Era

According to the previous explanation of the concepts, film industry aesthetics, due to their industrial characteristics, follow the producer-centered system, have star effect, and rely on film technology. The same applies to CNMB. However, with time, compared to similar films from the past, the latest five CNMB present certain new characteristics as follows.

\subsection{Different with the Past Film Industry Aesthetics - Current New Characteristics}

$\mathrm{CNMB}$, apart from as an industry, retain their charm and characteristics by upgrading their themes, because it is "the source of living water" and the soul of a film. At the same time, film industry aesthetics focuses on the narrative of genre films. However, the CNMB have the innovation of genre narrative and vivid descriptions of human details that differ from the norms of film production, which are mainly reflected in the following aspects.

\subsubsection{Upgraded Expression of Chinese Mainstream Values:}

With the passage of time, films have different cultural and era functions. The new environmental theme is also a reflection of the post-industrial era and society. From Bodyguards and Assassins and The Founding of A Republic in 2009 to Beginning Of The Great Revival in 2011 and The Founding of An Army in 2017, previous CNMB belonged to the category of historic revolutionary blockbusters. In recent years, with Chairman Xi Jinping's proposed concept of "China Dream" and "a Community of Shared Future for Mankind", films such as Operation Mekong (2016), Wolf Warrior 2 (2017), and Operation Red Sea (2018) started to present the themes in films. In addition, the theme of The Wandering Earth (2019) is heavily centered on the topic of global environmental protection. Films like My People, My Country and The Captain expressed the main melody, and also pay close attention to the realization of the "China Dream," under microscopic personal citizen life. The significance of the film is expanded by glorifying it with the theme of "a Community of Shared Future for Mankind" and the global environmental topic. CNMB such as these embody ideas that are advancing with present times, against the background and values of typical Chinese blockbusters.

\subsubsection{Attachment of Importance to the Young Generation Power in Mainstream Values:}

$\mathrm{CNMB}$ tend to features heroes or protagonists from the younger generation, which reflects the 
mainstream value of caring for the young generation and the attachment of importance to young power. The Chinese 80s generation is the first generation of the One Child Policy, while the 90s generation grew up with the development of media, and the 00s generation highlight their personal characteristics. They are the main force in building Chinese socialist modernization and the young force in establishing a Community of Shared Future for Mankind. CNMB typically always feature young heroes, for example, $\mathrm{Xu}$ Yichen, the co-pilot in The Captain, is a lively and playful character from the 90s generation. He adores Huang Jia, but Huang Jia only thinks of him as a boy. In the eyes of the pilot Liu Changjian, Xu Yichen is a recalcitrant child who cannot be entrusted with responsibility. Although he is young, he is calm, courageous, and fearless, and perseveres in the cold during the accident. After the accident, even though his eyes are seriously injured, but gives up the opportunity to be helped for other passengers. When he finally looks back at the broken aircraft, he appears to be more mature.

In the Daytime Meteor segment of My People, My Country, themes of youth, hope, faith, and the motherland link together. The young are persistent and yearning for ideals, and the older generation always taken care of and instruct the young, as evinced when the motherland Shenzhou 11 spacecraft capsule returns successfully, and they realize the importance of each other's faith and dreams. The film uses poetic and romantic film language to highlight care for the young generation and attachments of importance to young power.

In Operation Red Sea and Wolf Warrior 2, the Jiao Long members, Gu Shun, Tong Li, Li Dong, and Leng Feng are all young heroes who represent future power. This setting makes the audience feel that the 90s generation is accountable and has the ability to take on responsibility and tasks in the future. In other words, young people are the heroes and finally have a voice on screen.

\subsubsection{Genre Narrative of Innovation:}

The genre narrative of innovation is reflected in three aspects: addition of entertainment elements and universal values to the main theme, youth narrative, and the integration of various genre elements. First, the new mainstream blockbuster aesthetic characteristics include transformation, rewriting, dissemination, and the popularization of traditional films, commercial films, and art films[4]. Wolf Warrior 2, for example, features dramatic plots and the use of classic Hollywood narrative rules in the unfolding of main events. In the protagonists' fight with overseas terrorists in Africa, winning or losing are dramatically showed in detail. In the 
China's New Mainstream Blockbusters' Characteristics and Trends from the Perspective of Film Industry Aesthetics in the Post-Industrial Era

climax, the audience is led to think that the protagonists are finally safe and must only await the Chinese army to come and rescue them, but is later surprised when a sudden terrorist attack leads to scattered heavy casualties. This not only adds a sense of rescuing time urgency, but also increases details reflecting human nature. Silent sound effects combined with slow motion and the sacred girl song elicit many reactions. The dramatic fighting plots, special effects of explosions, and the use of Hollywood narrative rules reflect the full entertainment elements in the film, but the core event is the evacuation of overseas Chinese citizens by the Chinese People's Liberation Army, which is the main theme and reflects the universal value of internationalization and humanization in the artistic details.

In most contexts, the connotation of youth narrative has already surpassed its barrier of time, and has been sublimated and expanded into a very general cultural field. In other words, "youth" has become a good living state of individuals, a positive cultural ecology of society, and a high generalization of the spirit of an era. The youth narrative presents a new face of "depoliticization, derevolutionization, and declassization." As a kind of narrative, youth narrative has a long tradition, which is not only related to the narrative subject, but also a carrier of value and attitude towards life[6]. The last part reflects that the values in CNMB attach great importance to the power of the younger generation. In terms of narrative, it is mainly reflected in the motif setting which reflects the growth of the youth. For example, in The Captain, in order to save the lives of the entire aircraft crew during a crisis, the post-90s co-pilot $\mathrm{Xu}$ Yichen shows a calm demeanor and makes intelligent decisions as he makes a sacrifice-the young hero's growth process reflects the overall situation of heroic deeds. It presents a good individual living condition and positive social influence.

Third, a fusion of genre elements in a film. If the genre is objective, the audience and creators can reach a consensus on the film. According to the top 10 examples of the new mainstream blockbusters, the genres are rich, from action to science fiction and drama. The innovation of today's genre movies is that the same film combines elements from many genres. The Wandering Earth has elements of science fiction as well as disaster, adventure, and action. There is also a mix of action, military, and war elements in Wolf Warrior 2. This requires that the creators of $\mathrm{CNMB}$ must be familiar with all kinds of genre elements, from genre plots to characters.

\subsubsection{Vivid Details of Human Nature:}

This is also a new feature of CNMB in recent years. As per the red theme of films of the 
1990s, Operation Mekong would have been a very pure "Main Melody" film, but perhaps not as good as the current blockbusters. This is because in the past, collectivism, party spirit, organizational discipline, and other factors were dominant, thus ignoring the story and artistic quality of films. Filmmakers did not dare to advocate individual heroism, even in the 1990s. These films had a main theme, but the theme did not appeal to the audience. The main characters made the audience feel like they were gods rather than common humans like them. Currently, instead of conceptual motivations of previous mainland films guided by revolutionary slogans and political concepts, creators can surpass this narrative cleverly and flexibly[4].

An important aspect that transcends this narrative limitation is to focus on the expression of details of personal human nature of the characters, and to endow the works with fresh activity and authenticity. In Wolf Warrior 2 the protagonist Leng Feng stops the removers' hurt behavior to the household, but the removers threaten the safety of the family. Leng Feng thinks of the family's son who has been sacrificed on the battlefield, looking at the tears of the old and children. He does not hold back, he kicks the remover down in the car. Thus, he is discharged from the army. We know that although he has committed certain violations of discipline, his human nature is true and kind. Instead of being a cold-blooded soldier, he is warm and relatable. This also prepares the ground for his later action. Thus, the characters of $\mathrm{CNMB}$ are increasingly plump, three-dimensional, and flexible.

\section{Blockbusters' Future Trends in the Post-Industrial Era}

After studying $\mathrm{CNMB}^{\prime}$ characteristics, in order to develop them better, we should know their future trends. From the perspective of the era of post-industrialization, films experience several opportunities and challenges. Therefore, knowing the trends of developing CNMB in this era can be beneficial to the improvement of a country's cultural soft power and stable economic development.

At first, China's post-industrial society is a cooperative and open society. Under the impact of the wave of globalization, Chinese society cannot be satisfied with the achievements of the industrial society in political civilization and ideological construction, but should rebuild the ideology according to the reality of the post-industrial society. The process towards post-industrial society opens the door to a harmonious society. A harmonious society is a cooperative system, which requires a cooperative ideology. In the post-industrial era, with the formation of the global concept, people began to realize that universal cooperation-more than 
China's New Mainstream Blockbusters' Characteristics and Trends from the Perspective of Film Industry Aesthetics in the Post-Industrial Era

any conflict-can maximize individual interests and general human interest. It is believed that the conception of the cooperation has boundless and broad prospects[7].

Therefore, to develop the $\mathrm{CNMB}$, the creators must strengthen international regions cooperation, but this cooperation is better between the homology regions rather than between the east and the west. Due to cultural values and other differences between the east and the west, the cultural discount in the movie will be very large, and is therefore not easy to succeed. For homogenous countries such as China and South Korea in Asia, which have similar cultures and manners, the cultural discount reflected in the film will be relatively small and easy for the audience to accept, so the possibility of success is high.

Second, a key feature of China's post-industrial era is that the era of average industrial profit margins has officially begun. The return on investment of different industries and among different industries will become more average, and the average profit margin of industries will become larger. With the full play of the role of industrial average profit margin, capital flows between different industries will be faster, and the dependence and mutual support between different industries will increase. The rule of industrial average profit margin requires that industries and the fine molecule industries of the big industry can support each other. In line with this, enterprises are no longer between the relationship of pure perfect competition, but greater emphasis is on the interdependence between enterprises[8].

Therefore, from the perspective of industrial rule, the development of CNMB as a film industry needs to strengthen the cooperation between different industries, such as the cooperation with the knowledge, information, technology, and service industries. We will strengthen cooperation with the technology industry and incorporate more technical elements into film production, such as $3 \mathrm{D}$ and VR technologies. In the process of film-watching, we should strengthen cooperation with the service industry and provide better film-watching services from the customers' perspective. Filmmakers must also collaborate with technology and services to launch innovative projects in industries such as immersive cinema experiences. This is a feature of post-industrial society and an opportunity that is beneficial to the development of various industries, especially the film industry.

Third, as China is in a post-industrial society, from the perspective of the status and characteristics of the industry in the world pattern, the service demand target is mainly export-oriented. After years of insufficient domestic demand, export growth is seen as an important way to maintain high economic growth. As a result, exports account for a rising share of total output, and exports of goods alone account for more than a third of GDP in recent years[8]. 
However, $\mathrm{CNMB}$, as a film industry, are doing insufficiently in the aspect of export. By the overseas market box office data form below[9][10], we can see that the export of CNMB did not perform well which is opposite with the last paragraph's export-oriented trend in the post-industrial era. Firstly, it can be analyzed that in China's top 10, the five new mainstream movies rank well in the world, within the top 20, it is mainly China's domestic audience's contribution to it, while, the overseas market share is low. The overseas market accounted for $5.5 \%$ on average. My People, My Country and The Captain overseas markets only accounted for more than one percent. Second, taking the American market as an example, these films account for even less than $1 \%$ of the American market. However, we know that American mainstream Hollywood blockbusters have a large market share in China. Therefore, CNMB are doing well domestically, but are not recognized by audiences in overseas markets. CNMB' creators cannot be too complacent, as they have a certain distance towards the world, creation must be strengthened and it is better to show more vivid human nature features and universal value strategies in them. Furthermore, they should strengthen the cooperation of the international homology region to achieve output of characteristic culture and shape the national image while conveying Chinese values.

[Table 2] $\mathrm{CNMB}^{\prime}$ Box Office in the Global Market

\begin{tabular}{|c|c|c|c|c|c|c|}
\hline $\begin{array}{c}\text { Top 5 } \\
\text { CNMB'name } \\
\text { s }\end{array}$ & $\begin{array}{c}\text { Global box } \\
\text { office } \\
\text { ranking }\end{array}$ & $\begin{array}{c}\text { Global box } \\
\text { office }\end{array}$ & $\begin{array}{c}\text { American } \\
\text { box office }\end{array}$ & $\begin{array}{c}\text { American } \\
\text { box office } \\
\text { proportion }\end{array}$ & $\begin{array}{c}\text { The } \\
\text { Global box } \\
\text { office except } \\
\text { China }\end{array}$ & $\begin{array}{c}\text { proportion } \\
\text { of global } \\
\text { box office } \\
\text { except } \\
\text { China }\end{array}$ \\
\hline $\begin{array}{c}\text { The } \\
\text { Wandering } \\
\text { Earth }\end{array}$ & 13 & $\$ 699,760,773$ & $\$ 5,875,487$ & $0.8 \%$ & $\$ 3769970$ & $5.4 \%$ \\
\hline $\begin{array}{c}\text { My People, } \\
\text { My Country }\end{array}$ & 17 & $\$ 450,064,993$ & $\$ 2,356,683$ & $0.5 \%$ & $\$ 8314770$ & $1.9 \%$ \\
\hline $\begin{array}{c}\text { Operation } \\
\text { Red Sea }\end{array}$ & 13 & $\$ 579,330,426$ & $\$ 1,543,547$ & $0.3 \%$ & $\$ 63034517$ & $10.9 \%$ \\
\hline $\begin{array}{c}\text { Wolf } \\
\text { Warrior 2 }\end{array}$ & 7 & $\$ 870,325,439$ & $\$ 2,721,100$ & $0.3 \%$ & $\$ 67156201$ & $7.7 \%$ \\
\hline The Captain & 20 & $\$ 416,953,262$ & $\$ 706,572$ & $0.2 \%$ & $\$ 6332566$ & $1.5 \%$ \\
\hline
\end{tabular}

\section{Conclusions}

Several phenomenon-level films such as Wolf Warrior 2 appeared in recent years. The concept 
China's New Mainstream Blockbusters' Characteristics and Trends from the Perspective of Film Industry Aesthetics in the Post-Industrial Era

of CNMB needs to be established and developed as soon as possible. In post-industrial society in China, cultural soft power is becoming more important because the proportion of the tertiary industry exceeded the secondary industry. Developing CNMB is the best way to enhance the cultural soft power because they can convey the mainstream values of a country to the world. It also conforms to the development of China's national "Belt and Road" strategy. The concept of film industry aesthetics becomes more significant. The study finds that some places of $\mathrm{CNMB}$ are in consistent with the principles of film industry aesthetics: following the producer-centered system, star effect, dependence on film technology. While, as Chinese Chairman $\mathrm{Xi}_{\mathrm{i}}$ Jinping proposed the concepts of a Community of Shared Future for Mankind and China Dream in 2012, the themes of CNMB have been upgraded, presenting many new features. They are upgraded themes with the era advancing and new policies, paying more attention to the growth of the younger generation, more focus on genre narrative of innovation and increased vivid description details of human nature. Because of the trends of the era, the development of $\mathrm{CNMB}$ faces opportunities and challenges. In order to development $\mathrm{CNMB}$ better, we should know their future trends: strengthen the regional homology cooperation and different industries cooperation and pay attention to the overseas market. In this way, the country can project a new image and cultural values to the world and the domestic market. It is hoped that this study will also have reference values and inspiration functions to other countries' mainstream culture and values output in the film industry.

\section{References}

[1] J. Z. Ren, X. L. Fang, The Historical Process of China's Industrialization and the Response of Agricultural Ethics-Also Discussion on the Historical Opportunity of Post-Industrialization, Agricultural History of China, (2019), Vol.38, No.3, pp.3-10.

[2] X. G. Chen, The Discuss of Film Industry Aesthetics' Origins、 Theory Resources and System's Building, Journal of Shanghai University, (2019), Vol.36, No.1, pp.32-43.

[3] Q. Liu, The Building and Thinking for Chinese New Mainstream Blockbusters' Film Industry Aesthetics, Journal of Shanghai University, (2019), Vol.36, No.1, pp.51-62.

[4] W. Zhang, X. G. Chen, W. F. Zhao, Z. H. Liang, P. Y. C. Huang, J. L. Zhang, Difine-Flowing.Strategies-A Discussion of The Chinese New Mainstream Blockbusters, Contemporary Cinema, (2017), No.1, pp.4-18.

[5] X. G. Chen, L. N. Zhang, Film Industry Aesthetics' Principles And Creation, Film Art, (2018), No.1, pp.99-105. 
[6] Q. Liu, An Analysis of the Genre Narrative Strategy of China's New Mainstream Blockbusters from the Perspective of the Film The Founding of An Army, Comments from a Hundred Masters, (2019), No.4, pp.123-130.

[7] G. L. Shi, A Discussion On the Ideological Construction Under the Background of Post-Industrialization-Also a Comment on Professor Zhang Kangzhi's Ideology of Cooperation, Zhejiang Social Sciences, (2009), No.9, pp.65-70, pp.126-127, DOI: 10.14167/j.zjss.2009.09.008

[8] L. L. Wang, F. Zhao, On the Rules of Industrial Change in the Process of China's Post-Industrial Development, Economic Research Guide, (2011), No.34, pp.182-184.

[9] https://www.boxofficemojo.com/, Dec 30 (2019)

[10] http://www.endata.com.cn/BoxOffice/BO/History/history.html, Jan 2 (2020) 